\title{
Nutritional status and its association with quality of life among people living with HIV attending public anti-retroviral therapy sites of Kathmandu Valley, Nepal
}

\author{
Rajshree Thapa ${ }^{1 *}$, Archana Amatya ${ }^{1}$, Durga Prasad Pahari ${ }^{1}$, Kiran Bam² and M Sophia Newman ${ }^{3}$
}

\begin{abstract}
Background: Little evidence exists on the connections between nutrition, diet intake, and quality of life (QoL) among people living with HIV (PLHIV). The study aimed to estimate the prevalence of under-nutrition among PLHIV in Nepal, and identify risk factors and assess correlations with PLHIVs' QoL and nutritional status.
\end{abstract}

Methods: This quantitative cross-sectional study used Body Mass Index (BMI) as an indicator for nutritional status, and additional information on opportunistic infections (Ols), CD4 count, and World Health Organization (WHO) clinical staging was collected from medical records. Participants were asked to complete surveys on food security and QoL. Descriptive analysis was used to estimate the prevalence of under nutrition. To assess associations between nutrition status and independent variables, bivariate and multivariate analysis was completed. Spearman's rank correlation test was used to assess the association between nutritional status and QoL.

Results: One in five PLHIVs was found to be under nourished (BMI $\left.<18.5 \mathrm{~kg} / \mathrm{m}^{2}\right)$. Illiteracy, residence in care homes, CD4 cells count $<350$ cells $/ \mathrm{mm}^{3}$, Ols, and illness at WHO clinical stages III and IV were found to be significant predictors of under nutrition. BMI was significantly correlated with three domains of QoL (psychological, social and environmental).

Conclusion: Nutrition interventions should form an integral part of HIV care programs. Understanding the presence of OI, decline in CD4 count, and advancing WHO clinical stages as risk factors can be helpful in preventing under nutrition from developing. Longitudinal research is necessary to further explicate associations between nutritional status and QoL.

Keywords: Nutritional status, Quality of life (QoL), People living with HIV (PLHIV), Nepal, Food security

\section{Introduction}

Per Joint United Nations Programme on HIV and AIDS (UNAIDS), the number of people newly infected with Human Immunodeficiency Virus (HIV) each year is continuing to decline in most parts of the world. The new infections declined by 38 percent from 3.4 million in 2001 to 2.1 million in 2013 [1]. Meanwhile, care is increasing. The percentage of people living with HIV (PLHIV) who are receiving antiretroviral therapy (ART) have increased from around 10 percent in 2006 to

\footnotetext{
* Correspondence: raazshree.thapa@gmail.com

'Institute of Medicine, Maharajgunj Medical Campus, Tribhuwan University, Kathmandu, Nepal

Full list of author information is available at the end of the article
}

around 37 percent in 2013, with 12.9 million people receiving ART worldwide by the end of 2013 [1]. As a result, Acquired Immune Deficiency Syndrome (AIDS)related deaths have fallen by $35 \%$ since 2005 , when the highest number of deaths was recorded [2]. As a result of life-saving treatment, the number of PLHIV is rising in spite of falling rates of new infection. At the end of 2013, there were approximately 35 million PLHIV [2].

The role of HIV infection on nutrition was identified early in the epidemic [3]. Wasting is one of the most visible signs of malnutrition as patients progress from HIV to AIDS [3]. HIV was found to affect nutritional status by increasing energy requirements, reducing food intake, and adversely affecting nutrient absorption and metabolism 
[4]. Failing to meet nutritional needs may lead to decreased immunity and increased susceptibility to opportunistic infections (OIs), which can lead to further malnutrition. Additionally, nutrient intake can improve antiretroviral absorption and tolerance [5]. Receiving appropriate nutrition can help improve PLHIV's quality of life (QoL) [6]. Poor nutritional status in PLHIV speeds the disease progression, increases morbidity, and reduces survival time [7]. For these reasons, nutritional support should be a fundamental part of a comprehensive response to HIV and AIDS [8]. The World Health Organization (WHO) recommends ensuring micronutrient needs are met by increasing access to a diversified diet, fortified foods, and micronutrient supplements, particularly in areas where micronutrient deficiencies are endemic [8]. However, these clinical issues remain common, despite improvements in the treatment and survival of PLHIV [7].

Similarly, food insecurity and HIV and AIDS are intertwined in a vicious cycle [9]. Food insecurity is the condition of not having physical or economic access to enough food to be productive and healthy. Each condition increases the vulnerability to and worsen the severity of the other [9]. Among PLHIV, food insecurity is associated with incomplete HIV-1 RNA suppression, CD4 decline, increased opportunistic infections, hospitalizations, and HIV-related mortality [10]. Good nutrition for PLHIV has been proven to increase resistance to infection, help PLHIV maintain weight, and improve QoL, drug compliance, and drug efficacy $[10,11]$.

In a chronic disease like HIV and AIDS the QoL of the patients is also important [12]. The WHO defines QoL as "an individuals' perception of their position in life in the context of their culture and value systems in which they live and in relation to their goals, standards, expectations and concerns" [13]. Health Related QoL (HRQoL) comprises the components of QoL that are directly related to health status. Studies have reported a strong association between HRQoL and socioeconomic characteristics [14,15] and health related indicators [16] in resource-poor settings. Various symptoms, including wasting, are known to potentially reduce QoL among PLHIV [17]. But the relationship between nutritional status and QoL are not yet clearly defined [10], and the investigation of the relationship between food security and HRQoL among PLHIV is just beginning to emerge $[10,11,18]$. In particular, there is a lack of clarity on the dimensions of food security critical for improving HRQoL for PLHIV. By the latest estimate (2013), the current prevalence of HIV is 0.23 percent among adults (aged 15-49 years) in Nepal [19]. A total of 40,720 people are estimated to be living with HIV [19]. There has been a large decline in new infections annually, from 8,039 in 2000 to 1,408 in 2013 [19]. Per the country's Millennium Development Goal 2013 progress report, around 28.7 percent of PLHIV with advanced HIV infection are now receiving antiretroviral combination therapy, a figure that increased from 21 percent in 2010 [20].

A recent study from the Food and Agricultural Organization (FAO) shows that in Nepal, around 3.7 million people, representing 16.4 percent of the rural population of Nepal, are food insecure [21]. The number of these who are PLHIV is difficult to ascertain. In a food insecure area, assessing food security during clinical care for the PLHIV population is important. This study aims to identify nutritional status of PLHIV in Nepal, to identify how food security may impact nutritional status, and to clarify the relationship between nutritional status and HRQoL and PLHIV in Nepal.

\section{Methods}

\section{Study design}

This is a cross-sectional study using quantitative domain to assess the relationship between nutrition status and other variables.

\section{Study location and timeframe}

We conducted this study at two public ART sites, Tribhuvan University Teaching Hospital (TUTH) and Sukraraj Tropical and Infectious Disease Control Hospital (STIDH). These were selected out of four public ART sites in Kathmandu Valley, Nepal, that provide ART. TUTH and STIDH were taken purposively based on the high number of PLHIVs registered at these two sites. Data was collected for six months, from July to December 2013.

\section{Study population and sampling technique}

The study population was PLHIV who are accessing services from these health institutions. Inclusion criteria were a diagnosis of HIV at least six months prior to the study period, age 18 years or more, and ability to consent to the study. Both ART and pre-ART clients were included, and for those participants on ART, only those clients who have been taking ART for at least six months prior to the study period were included. As per the national ART guideline [22], those PLHIV in WHO stages III and IV or with CD4 cells count less than 350 cells $/ \mathrm{mm}^{3}$ are enrolled on ART.

The exclusion criteria were PLHIV who are severely sick or unable to respond. In addition, pregnant women were excluded and those clients who had started ART within six months of the study were excluded. This last exclusion was to allow for accurate comparison of ART and pre-ART clients.

Other studies have established estimated malnutrition prevalence among PLHIV of $30 \%$ [23,24]. With a confidence interval of $95 \%$, an allowable error of $5 \%$ and a $5 \%$ non-response rate, the total calculated sample size was 340. The sample was determined using formula by Kothari [25]. 
Clients on ART were identified via the ART and preART registers maintained at the sites, and a random sampling technique was employed to select 340 prospective research participants. These 340 people were contacted for study recruitment. As PLHIV is recommended for the regular CD4 cells count monitoring, prospective participants were approached during their visit at health facility for ART or pre-ART services. At first contact, researchers briefly screened prospective participants to ensure that participants enrolled in the study were those who had been diagnosed with HIV for at least six months, and that those who were on ART, had been on the regimen for a minimum duration of six months.

\section{Ethics and consent}

To accommodate the sensitivity of the issue and maintain participant confidentiality, verbal informed consent was taken from each participant before data collection. The informed consent process included a verbal explanation describing the purpose of the study, potential risks and benefits of participating, procedures for maintaining confidentiality, and the participants' right to refuse to participate. Each participant was then given an opportunity to provide verbal consent, and this was recorded by the research team.

Acknowledging the sensitivity of the issue, researcher behavior that reinforced prevailing stigma and discrimination against PLHIVs was strictly prohibited. Sensitivity and appropriate language were included as topics in researcher preparation prior to data collection.

This informed consent followed the ethical norms and values stated in the National Ethical Guidelines for Health Research in Nepal (2001) [26]. Ethical approval was obtained from the Institutional Ethical Review Board (ERB) of the Institute of Medicine, Tribhuvan University.

\section{Data collection instruments}

The study collected anthropometric data: a reference weight and height measured by standard methods, and a body mass index (BMI) calculated as a basic indicator of nutritional status. CD4 cell counts and WHO HIV and AIDS clinical staging data were taken from the health records of each participant. Each participant's ART use status was also taken from client's personal ART and pre-ART records and was confirmed at the time of recruitment. Clinical information such as the enrollment in ART, time since diagnosis, WHO clinical staging, and TB co-infection at any time after the diagnosis of HIV were recorded from individual clients records and triangulated with the ART and pre-ART registers maintained at the service facility.

Following this, each participant completed a questionnaire. The participant's demographic information (age, literacy, educational level, marital status, caste, religion, and household status) and health behaviors (tobacco use and alcohol consumption) were included as self-report items on the first part of the questionnaire. To assess the QoL of the patients, the 26-item WHOQOL-HIV BREF [27] was used. This instrument has been utilized in many studies to determine the health related quality of life among PLHIV [28,29]. The instrument uses 26 items and measures QoL across four domains: physical well-being, psychological well-being, level of independence, and environment. The participant ranked their QoL on each item on a scale of one to five, where higher scores indicated greater QoL.

Household food insecurity was measured using Household Food Insecurity Access Scale (HFIAS) [30], a wellvalidated instrument used to measure household food insecurity in many countries [31-33]. It consists of nine questions on experiences of food insecurity, with possible responses of never, rarely, sometimes, or often. The highest score for HFIAS is 27; the higher the score, the greater the food insecurity.

The data collection tools were translated into the Nepali language and pre-tested with $10 \%$ of the sample size in the ART center at TUTH in Kathmandu. These samples were not included in the final analysis. Factual information obtained from these samples was cross-checked with ART and Pre-ART registers at the study sites. After the pretesting, various questions relating to co-infections were omitted, as only TB was found to have been recorded accurately. Similarly questions pertaining to fortified food supply from the ART center was also omitted as the supply of the fortified food was interrupted for more than six months during the time of study and very few study participants could actually recall of the receipt. Additionally, face validity was checked during the pretest and modifications were made to increase cultural competency in the question phrasing. Finally, the pre-testing process included discussion of stigma and discrimination with pretesting participants, and their feedback was integrated into ensuring sensitive language and behavior was maintained in the data collection processes.

\section{Statistical analysis}

Every completed questionnaire was reviewed at the end of each day to ensure its consistency and completeness. After data collection, 10 percent of the sample was randomly cross-checked for accuracy, and where errors were found, these were corrected. All recorded data was coded to facilitate data entry process. BMI was calculated from the height and weight using the standard formula: $\mathrm{BMI}=$ Weight $(\mathrm{kg}) /$ Height $^{2}(\mathrm{~m})$. The WHOQOL- HIV BREF [27] was used to produce a QoL profile derived from four domain scores denoting facets of an individual's perceived QoL. The mean score of items within each domain is used to calculate the domain score. Mean scores are then multiplied by four in 
order to make domain scores comparable with the scores used in the WHOQOL-100, a commonly used scale. The instruments' guidelines for checking and cleaning data and computing domain scores were rigorously followed.

Where more than $20 \%$ of data is missing from a questionnaire, the questionnaire was discarded. Where an item is missing, the mean of other items in the domain was substituted. Where more than two items are missing from the domain, the domain score was not calculated (with the exception of domain 3, where the domain could only be calculated if $<1$ item is missing). Finally, two items were examined separately: a question about an individual's overall perception of QoL and a question about an individual's overall perception of their health.

The calculation of the household food security score was based on the HFIAS version 3 [30]. The instrument had a top score of 27 points, where greater scores indicate more severe food insecurity. Four strata of food security were created based on the guideline (secure, mildly insecure, moderately insecure, and severely insecure). For the analysis purpose HFIA category 1 is termed as food secure and HFIA category 2 to 4 are categorized as food insecure. To assess associations between nutrition status and independent variables, bivariate and multivariate analysis was completed. Spearman's rank correlation test was used to assess the association between nutritional status and QoL.

\section{Results}

\section{Total participants}

A total of 340 PLHIV were contacted for interviews in the two public ART sites in Kathmandu Valley; 120 were approached in TUTH and 220 were approached in STIDH. Of these, 15 people declined to participate. The response rate was therefore $95.58 \%$ (325/340). The major reasons for non- participation in TUTH was fear of breach of confidentiality $(n=6)$. Many of the clients who declined said they had not disclosed their status to anyone. In STIDH the major reason for non-participation was inability to commit the necessary amount of time $(\mathrm{n}=5)$, although other feared disclosure of their status or were disinterested in the study $(n=4)$.

Among the 325 interviews taken, 24 were not complete. Thus, 301 samples were taken for final analysis, for a final response rate of $88.56 \%$. Of these, 101 participants from TUTH and 200 participants from STIDH completed the study.

\section{Population characteristics}

The mean age of the population was 36.2 years with the standard deviation of 8.2 years. The majority of respondents (61.1\%) were male. About one-third (30.2\%) had completed primary level education or less, and around 77 percent were able to read and write. The majority were married (70.7\%). A considerable percent were widows or widowers (8.6\%).
With respect to caste (the local equivalent of socioeconomic class); Janajatis (around 41\%) accounted for the highest proportion of the PLHIVs seeking treatment at these sites, followed by Brahmins/Chettri (33\%) and Dalits (18.6\%). The majority were Hindus (70.8\%), followed by Buddhists (15.9\%), Christians (7\%), and other faiths, mainly Kirat (3\%) and Muslim (1.3\%). Most resided with their family (87\%), although $9 \%$ were living in group homes run by charitable organizations or in prison, and another $4 \%$ were living alone in rented homes. Background characteristics of the study participants are given in Table 1.

\section{Nutritional status of PLHIV}

To determine nutritional status, BMI was calculated. The standard cut-offs were used: $<18.5 \mathrm{~kg} / \mathrm{m}^{2}$ is underweight, $18.5-24.9 \mathrm{~kg} / \mathrm{m}^{2}$ is normal, and greater than or equals to $25.0 \mathrm{~kg} / \mathrm{m}^{2}$ is considered overweight. Out of the 301 samples analyzed, 60 participants had BMI less than $18.5 \mathrm{~kg} / \mathrm{m}^{2}$. Thus $19.93 \%$ of the PLHIVs visiting the ART centers in Kathmandu valley were undernourished. Females were found to be more undernourished than the males; 17.4 percent of males and 23 percent of females had BMI less than $18.5 \mathrm{~kg} / \mathrm{m}^{2}$. On the other hand, 29 PLHIV (9.7\%) were found to be overweight. Details are presented in Table 2.

\section{Socioeconomic, behavioral factors, HIV related factors and nutrition status}

The association between the various socioeconomic and HIV related variables and nutritional status was assessed through binary logistic regression. The statistical significance was tested at $95 \%$ confidence interval or $\mathrm{p}$-value $<0.05$.

Among the demographic variables, age, gender, ethnicity, religion and occupation were found to have no significant association with nutritional status of the PLHIV. The mean age of the study participants was $36.2 \pm 8.2$, and the age of the study participants was not significantly associated with the nutritional status of the PLHIV.

Education status was found to be significantly associated with the nutritional status of PLHIV. Those PLHIV who were illiterate were almost 2.5 times more likely to be undernourished than those who were literate (Crude OR $=2.45$; 95\% C.I, 1.32-4.54).

During bivariate analysis, marital status was a significant factor for under-nutrition. Those who are unmarried were 2.7 times more likely to be undernourished than those who were married. Similarly, those PLHIV living single or at care homes were around three times more likely to be undernourished than those who resided with their families (Crude OR =3.45; 95\% C.I, 1.68-7.05).

Household access to food is a key indicator for predicting under-nutrition. Of the 301 clients, 71 participants (23.6 percent) were found to have some food insecurity (denoted as levels 2, 3, or 4 on a scale of one to four). Households with food insecurity were more than twice as likely to be 
Table 1 Socio demographic characteristics of study participants

\begin{tabular}{l} 
Variables \\
\hline Treatment sites \\
TUTH \\
STIDH \\
Age (Mean \pm SD ) \\
$\leq 36$ years \\
$>36$ years
\end{tabular}

Gender

Male

Female

Literacy status

Yes

No

Educational level

Illiterate

Primary

Secondary

Higher secondary and above

Marital status

Married

Unmarried

Divorced

Separated

Widower/Widowed

Caste

Dalit

Terai Janajati

Janajati

Brahmin/Chettri

Other

\section{Place of residence}

Residing with family

Residing with a care organization

Residing alone

Religion

Hindu

Muslim

Buddhists

Christian

Others

Occupation

Agriculture

Labor

Service

N (\%)

101(33.6\%)

200(66.4\%)

$36.2 \pm 8.2$

159(52.8\%)

142(47.2\%)

184(61.1\%)

117(38.9\%)

233(77.4\%)

68(22.6\%)

68(22.6\%)

$91(30.2 \%)$

68(22.6\%)

$74(24.6 \%)$

213(70.7\%)

$38(12.6 \%)$

12(4.0\%)

12(4.0\%)

26(8.6\%)

$57(18.6 \%)$

12(4.0\%)

123(40.9\%)

100(33.2\%)

9(3.0\%)

262(87.0\%)

$27(9.0 \%)$

$12(4.0 \%)$

219(70.8\%)

$4(1.3 \%)$

48(15.9\%)

21(7.0\%)

9(3.0\%)

$54(17.9 \%)$

23(7.6\%)

$61(20.3 \%)$
Table 1 Socio demographic characteristics of study participants (Continued)

\begin{tabular}{ll}
\hline Self-business & $46(15.3 \%)$ \\
Household work & $61(20.3 \%)$ \\
No work & $35(11.6 \%)$ \\
Others & $21(7.0 \%)$ \\
Smoking habits & \\
Regular smokers & $111(36.9 \%)$ \\
Non smokers & $190(63.1 \%)$ \\
Alcohol use & \\
Regular alcohol user & $98(22.6 \%)$ \\
Non alcoholic & $203(67.4 \%)$ \\
\hline
\end{tabular}

undernourished as those PLHIV with adequate access to food (Crude OR = 2.75; 95\% C.I, 1.50-5.04).

Behavioral factors such as smoking and alcohol use were not found to be significantly associated with nutrition status. The association between various sociodemographic and behavioral factors and nutrition status is presented in Table 3.

\section{HIV-related variables and nutritional status}

Various factors related to the HIV infection such as the duration from diagnosis, ART status, and duration on ART, presence of any OIs and WHO stage was integrated into study analyses. During bivariate analysis, no significant association was found between the time since diagnosis and nutritional status.

Differences between nutritional status and enrollment in the ART were assessed. A higher proportion of preART PLHIV were undernourished than those on ART. Out of 40 PLHIV on pre-ART, ten were undernourished (25\%). In comparison, out of 261 PLHIV on ART, 50 were undernourished (19.2.\%). This association, however, was not statistically significant (Crude OR $=0.71 ; 95 \%$ C.I, 0.31-1.02) (Table 3).

\section{Multivariate analysis of associated factors}

Those variables significantly related with under-nutrition (p-value $<0.05$ ) in bivariate analysis were further subjected into multivariate analysis using a logistic regression model. Only the variables found significant at $95 \%$ confidence interval in bivariate analysis were used for multivariate analysis. Binary logistic regression using the

\section{Table 2 Nutritional status of PLHIV}

\begin{tabular}{ll}
\hline BMI & N (\%) \\
\hline BMl $<18.5 \mathrm{~kg} / \mathrm{m}^{2}$ (underweight) & $60(19.9 \%)$ \\
$\mathrm{BMI}\left(18.5-24.4 \mathrm{~kg} / \mathrm{m}^{2}\right)$ (Normal weight) & $212(70.4 \%)$ \\
$\mathrm{BMI}\left(>24.4 \mathrm{~kg} / \mathrm{m}^{2}\right.$ (overweight) & $29(9.7 \%)$ \\
Total & $301(100 \%)$ \\
\hline
\end{tabular}


Table 3 Socioeconomic factors associated with the nutritional status

\begin{tabular}{|c|c|c|c|c|c|c|c|}
\hline Variables & Categories & $\begin{array}{l}\text { Underweight } \\
n(\%) n=60\end{array}$ & $\begin{array}{l}\text { Well-nourished } \\
n(\%) n=241\end{array}$ & $\begin{array}{l}\text { Crude OR } \\
(95 \% \text { C.I.) }\end{array}$ & P-value & $\begin{array}{l}\text { Adjusted OR } \\
\text { (95\% C.I.) }\end{array}$ & P-Value \\
\hline \multirow[t]{2}{*}{ Age } & $\leq 36$ years* & $41(25.8)$ & $118(74.2)$ & $0.55(0.28-1.09)$ & 0.088 & & \\
\hline & $>36$ years & $19(13.4)$ & $123(86.6)$ & 1 & & & \\
\hline \multirow[t]{2}{*}{ Educational status } & Illiterate & $22(32.4)$ & $46(67.6)$ & $2.45(1.33-4.54)$ & 0.004 & $2.31(1.10-4.82)$ & 0.027 \\
\hline & Literate & $38(16.3)$ & $195(83.7)$ & 1 & & & \\
\hline \multirow[t]{2}{*}{ Gender } & Female & $28(23.9)$ & $89(76.1)$ & $1.49(0.85-2.64)$ & 0.235 & & \\
\hline & Male & $32(17.4)$ & $152(82.6)$ & 1 & & & \\
\hline \multirow[t]{3}{*}{ Marital status } & Unmarried & $13(34.2)$ & $25(65.8)$ & $2.76(1.36-5.59)$ & 0.005 & $2.14(0.94-4.88)$ & 0.701 \\
\hline & $\begin{array}{l}\text { Separated/widowed/ } \\
\text { divorced }\end{array}$ & $16(32.0)$ & $34(68.0)$ & $0.91(0.31-2.22)$ & 0.827 & $0.74(0.24-2.29)$ & 0.603 \\
\hline & Married & $31(14.6)$ & $182(85.4)$ & 1 & & & \\
\hline \multirow[t]{2}{*}{ Ethnicity } & Dalits & $6(10.5)$ & $51(89.5)$ & $2.42(0.98-5.98)$ & 0.054 & & \\
\hline & Non- Dalits & $54(24.1)$ & $190(75.9)$ & 1 & & & \\
\hline \multirow[t]{3}{*}{ Wealth quintile } & Middle class & $20(19.6)$ & $82(80.4)$ & $1.30(0.65-2.61)$ & 0.458 & & \\
\hline & Lower class & $22(22.2)$ & $77(77.8)$ & $1.17(0.54-2.31)$ & 0.649 & & \\
\hline & Upper class & $18(18.0)$ & $82(82.0)$ & 1 & & & \\
\hline \multirow[t]{2}{*}{ Religion } & Hindu & $44(20.1)$ & $175(79.9)$ & $0.76(0.41-1.41)$ & 0.391 & & \\
\hline & Other than Hindu\# & $16(19.5)$ & $66(79.1)$ & 1 & & & \\
\hline \multirow[t]{2}{*}{ Residence } & Care homes/Single & $16(41.0)$ & $23(59.0)$ & $3.45(1.69-7.05)$ & 0.009 & $4.47(1.79-11.15)$ & 0.001 \\
\hline & Family & $44(16.8)$ & $218(83.2)$ & 1 & & & \\
\hline \multirow[t]{2}{*}{ Alcohol use } & No & $44(21.7)$ & $159(78.3)$ & $0.71(0.38-1.33)$ & 0.278 & & \\
\hline & Yes & $16(16.3)$ & $82(83.7)$ & 1 & & & \\
\hline \multirow{2}{*}{$\begin{array}{l}\text { Associated with PLHIV } \\
\text { network }\end{array}$} & No & 43 (28.6) & $150(71.4)$ & $1.54(0.83-2.85)$ & 0.175 & & \\
\hline & Yes & $17(15.7)$ & $91(84.3)$ & 1 & & & \\
\hline \multirow[t]{2}{*}{ Household food security } & Food insecure & $24(33.8)$ & $47(66.1)$ & $2.75(1.50-5.05)$ & 0.001 & $2.89(1.39-5.95)$ & 0.004 \\
\hline & Food secure & $36(15.6)$ & $194(84.3)$ & 1 & & & \\
\hline \multirow[t]{2}{*}{ Smoking habits } & No & $41(21.6)$ & $149(78.4)$ & $0.75(0.41-1.37)$ & & & \\
\hline & Yes & $19(17.1)$ & $92(82.9)$ & 1 & & & \\
\hline \multicolumn{8}{|l|}{ HIV related factors } \\
\hline \multirow[t]{2}{*}{ Duration from diagnosis } & $\leq 12$ months & $47(24.7)$ & $143(75.3)$ & $0.57(0.32-1.03)$ & 0.062 & & \\
\hline & $>12$ months & $13(11.7)$ & $98(88.3)$ & 1 & & & \\
\hline \multirow[t]{2}{*}{ ART } & Yes & $50(19.2)$ & $211(80.8)$ & $0.71(0.33-1.55)$ & 0.391 & & \\
\hline & No & $10(25.0)$ & $30(75.0)$ & 1 & & & \\
\hline \multirow[t]{2}{*}{ CD4 count } & $>350$ cells $/ \mathrm{mm}^{3}$ & $17(10.4)$ & $146(89.6)$ & $0.26(0.14-0.48)$ & 0.000 & $0.26(0.13-0.56)$ & 0.000 \\
\hline & $\leq 350$ cells $/ \mathrm{mm}^{3}$ & $43(31.2)$ & $95(68.8)$ & 1 & & & \\
\hline \multirow[t]{2}{*}{ ART duration } & $\leq 12$ months & $16(21.1)$ & $60(78.9)$ & $0.914(0.46-1.81)$ & 0.797 & & \\
\hline & $>12$ months & 44 (19.6) & $181(80.4)$ & 1 & & & \\
\hline \multirow[t]{2}{*}{ TB infection } & Yes & $17(40.4)$ & $25(59.6)$ & $3.42(1.70-6.86)$ & 0.001 & $3.16(1.43-7.01)$ & 0.005 \\
\hline & No & $43(16.6)$ & $216(83.4)$ & 1 & & & \\
\hline \multirow[t]{2}{*}{ WHO clinical stage } & III/IV & $41(29.1)$ & $100(70.9)$ & $3.04(1.67-5.55)$ & 0.000 & $2.09(1.04-4.21)$ & 0.038 \\
\hline & $|/| \mid$ & 19 (11.9) & 141 (88.1) & 1 & & & \\
\hline
\end{tabular}

1 = Reference Category.

*Mean value was used.

\#Others include Muslim, Christian, Buddhist and Kirat.

Variables (education, age, gender, marital status, residence, Ols, WHO clinical stage, household food security and CD4 cell counts) are adjusted to minimize the effect of possible confounders in multivariate analysis. 
enter method was applied to get the final model, and the Hosmer and Lemeshow test was done to test goodness of fit. The model was found to be fit $(\mathrm{p}=0.153>0.05)$. Multivariate analysis was performed to examine the independent effect of each of the significant independent variables in bivariate analysis with the effect of other variables remaining constant. In the multivariate analysis, the coefficient of determination $\left(R^{2}\right)$ was 0.67 .

In bivariate analysis, marital status was found to be significantly associated with under-nutrition. However, this relation was not significant when subjected to multivariate analysis.

The association of literacy status with under-nutrition was found to be significant. Illiterate people were 2.3 times as likely to be undernourished as people who could read and write (Adjusted OR = 2.31; 95\% C.I, 1.10-4.82).

PLHIVs' residence with their family members, alone, or at care homes also determines their nutritional status. Residing with family members provides a protective effect against under-nutrition. Those participants who resided alone or in care homes were more than four times as likely to be undernourished than those living with their family members (Adjusted OR =4.47; 95\% C.I,1.79-11.14). Food security remains the prominent factor affecting nutritional status even when subjected to multivariate analysis (Adjusted OR $=2.88$; 95\% C.I, 1.39-5.95).

CD4 count was a significant factor associated with under-nutrition. PLHIVs with CD4 counts of 350cells $/ \mathrm{mm}^{3}$ or more were $74 \%$ less likely to be undernourished than their counter parts (Adjusted OR $=0.26$; 95\% C.I, 0.120.55). Similarly, WHO clinical stages III and IV were found to be significant factors associated with under nutrition. PLHIVs in stage III and IV were more than twice as likely to be under-nourished than WHO stage I and II (adjusted $\mathrm{OR}=2.09$, 95\% C.I, 1.04-4.21). Previous OIs with tuberculosis was also found to be the prominent risk factor for under nutrition (Adjusted $\mathrm{OR}=3.16$, 95\% C.I, 1.42-7.0). The multivariate analysis is presented in Table 3.

\section{Health-related QoL of PLHIV QoL descriptive statistics}

QoL was measured using the WHOQolBREF [27]. Four domains capture different aspects of health-related QoL: physical health (including medical issues, pain, work capacity, and other aspects), psychological health (including negative and positive feelings, self-esteem, spirituality, and cognitive functions), social relationships (including social support and intimate relationships), and environment (including financial resources, safety, physical surroundings, and more).

\section{Socio demographic factors and QoL}

In the bivariate analysis of demographic variables and QoL scores, a significant difference in the QoL mean scores of male and female participants was noted. Males reported higher mean scores than females. Literate participants were also found to have higher QoL scores. Other demographic characteristics, such as marital status, religion and occupation, showed no significant differences in QoL scores.

Mean QoL scores were also found to be significantly higher among PLHIV with higher CD4 counts and those who were at WHO clinical stage I and II. The association, however, was not significant in the physical health and social domains.

The mean scores for all four different domains were found to be lower among the undernourished than those PLHIV having a BMI $>18.5 \mathrm{~kg} / \mathrm{m}^{2}$ and this difference was significant for psychological, social and environmental domains (Table 4).

\section{Correlation between QoL and nutritional status}

A Spearmen Rank correlation test was carried out to observe if there was any correlation between nutritional status and QoL. A positive correlation was seen between weight and all four domains, as well as between BMI and all four domains. However, the correlation is weak $(<0.3)$ throughout. Notably, height is also found to be significantly correlated with three domains (psychological, level of independence and environment) of QoL (Table 5).

\section{Discussion}

\section{Nutritional status of PLHIV}

The study estimates the rate of under-nutrition among PLHIVs and assesses correlations to other elements of their lives. The role of HIV infection on nutrition has been well-documented. Wasting is one of the most visible signs of malnutrition in patients who progress to AIDS [34]. Food insecurity, the condition of not having physical or economic access to sufficient food to meet dietary needs for a productive and healthy life [35], remains a common problem among PLHIV despite advances in their treatment and survival. However, the complex interactions of under-nutrition, food insecurity, QoL, and health status are not well-documented.

HIV affects the proportion of population already struggling with malnutrition and food security. In 2011, the Nepal Demographic and Health Survey (NDHS) reported that $18 \%$ of all adult females in Nepal were malnourished. The study suggests that HIV-infected women are more vulnerable to malnutrition, with 23 percent of female participants having BMI less than $18.5 \mathrm{~kg} / \mathrm{m}^{2}$ [36].

According to the WHO, nutritional support should be fundamental to a comprehensive response to HIV and AIDS [37]. Poor nutritional status in PLHIV is associated with disease progression, increased morbidity, and reduced survival, even when ART is available [38]. A study in the United States found that micronutrient 
Table 4 Mean scores of different domains of the QoL

\begin{tabular}{|c|c|c|c|c|c|}
\hline Variables & Categories & Physical domain \pm SD & $\begin{array}{l}\text { Psychological } \\
\text { domain } \pm \text { SD }\end{array}$ & Social domain \pm SD & $\begin{array}{l}\text { Environmental } \\
\text { domain } \pm \text { SD }\end{array}$ \\
\hline \multirow[t]{2}{*}{ Gender } & Male & $48.8 \pm 9.8$ & $46.5 \pm 10.8$ & $43.8 \pm 13$ & $44.5 \pm 10.9$ \\
\hline & Female & $45.3 \pm 8.3$ & $41.7 \pm 10.2$ & $38.5 \pm 12.3$ & $40.2 \pm 9.5$ \\
\hline \multirow[t]{2}{*}{ Education } & Illiterate & $45.8 \pm 9.6$ & $45.8 \pm 10.6$ & $43.0 \pm 13.4$ & $44.5 \pm 10.7$ \\
\hline & Some education & $40.6 \pm 7.8$ & $40.6 \pm 10.6$ & $36.6 \pm 11.3$ & $37.3 \pm 8.2$ \\
\hline \multirow[t]{2}{*}{ CD4 count (cells $/ \mathrm{mm}^{3}$ ) } & $<350$ & $46.4 \pm 10.10$ & $43.3 \pm 11.4$ & $41.0 \pm 12.9$ & $41.6 \pm 11.0$ \\
\hline & $\geq 350$ & $48.6 \pm 8.5$ & $46.2 \pm 9.8$ & $42.6 \pm 13.4$ & $44.3 \pm 9.8$ \\
\hline \multirow[t]{2}{*}{ WHO stage } & $\mathrm{I} / \mathrm{II}$ & $46.2 \pm 8.0$ & $41 \pm 8.9$ & $39 \pm 9.3$ & $40 \pm 8.2$ \\
\hline & III/IV & $48.38 \pm 8.4$ & $46 \pm 10.6$ & $43 \pm 14.5$ & $44.9 \pm 11.2$ \\
\hline \multirow[t]{2}{*}{ BMI $\left(\mathrm{Kg} / \mathrm{m}^{2}\right)$} & $<18.5$ & $45.41 \pm 9.4$ & $41.5 \pm 11.7$ & $36.06 \pm 12.3$ & $38.4 \pm 9.4$ \\
\hline & $\geq 18.5$ & $47.9 \pm 10.6$ & $45.4 \pm 10.4$ & $43.1 \pm 13.0$ & $43.9 \pm 10.6$ \\
\hline
\end{tabular}

supplements significantly increased CD4 count among PLHIV [39], and studies among HIV-infected adults in Haiti, Kenya, Malawi and Zambia have demonstrated significant positive effects of macronutrient supplementation on adherence to antiretroviral medication, weight gain and CD4 counts [38-42]. Similarly, in food-insecure settings, food support programs (increasing total calories) are often required in addition to nutrition support (increasing specific micronutrients) to optimize health outcomes in PLHIV [38]. This supports the idea of nutritional support to PLHIVs in countries (like Nepal) where food insecurity is endemic.

\section{Factors associated with under nutrition among PLHIV}

Various socio-demographic and HIV-related factors determine the nutritional status of PLHIVs. Education status was significantly associated with nutritional status, in that illiterate people were more likely to be undernourished. Previous studies of underlying factors in under-nutrition among the illiterate demonstrate that differences may include their dietary pattern, their understanding on the disease processes, and ART adherence [43]. A study carried out in Ethiopia in 2013 indicates that occupation and economic status might account for the vulnerability of illiterate people to under nutrition [44]. In this study, no significant association was seen between under-nutrition and socioeconomic status.

Table 5 Correlation between the nutritional status and QoL

\begin{tabular}{lllll}
\hline $\begin{array}{l}\text { Domains/ } \\
\text { Nutritional } \\
\text { status }\end{array}$ & Physical & Psychological & $\begin{array}{l}\text { Level of } \\
\text { independence }\end{array}$ & Environment \\
\hline Weight & $0.124^{*}$ & $0.236^{*}$ & $0.272^{*}$ & $0.262^{*}$ \\
Height & 0.059 & $0.148^{*}$ & $0.207^{*}$ & $0.164^{*}$ \\
BMI & $0.136^{*}$ & $0.154^{*}$ & $0.208^{*}$ & $0.215^{*}$ \\
\hline
\end{tabular}

*Significant at $95 \% \mathrm{Cl}, \mathrm{P}$ value $<0.05$.
Independent of all other variables, WHO clinical stages III and IV have significant effects on the likelihood of malnutrition development. Malnutrition is usually encountered at the advanced phase of HIV infection. An anthropometric measurement like BMI is lower in symptomatic patients as classified by WHO HIV disease stages [45]. Since disease status could modulate the immunological responses to HIV infection over time [44], further research with longitudinal design can be helpful in assessing the effect of malnutrition on HIV infection progression.

It was found that an OIs (tuberculosis) was an independent risk factor for under nutrition. Similar other studies support the findings that TB is associated with under nutrition [46-49]. The HIV-induced immune impairment and heightened subsequent risk of OIs can worsen nutritional status [50]. This exemplifies the importance of managing patients with OIs promptly.

Regarding CD4 count, we found that PLHIV with more than 350 cells $/ \mathrm{mm}^{3}$ were more well-nourished than PLHIV with less than or equal to 350 cells $/ \mathrm{mm}^{3}$. Since this is a cross-sectional study, some longitudinal study can better explain the relationship between CD4 count and nutritional status. The same is true for understanding the relationship between OIs and under nutrition.

\section{Correlation between nutritional status and health related QoL}

There are very little evidence linking nutritional status and health related QoL. In our study all three parameters (height, weight, and BMI) were found to be significantly associated with the domains of QoL. A cross-sectional study carried out at West Bengal, India, among HIV-positive women in 2012 similarly showed that QoL scores were correlated positively with all the parameters of nutritional status [12]. The correlation of height and QoL may indicate that lifelong undernourishment resulting in stunting, rather than current HIV status, may correlate with lower 
levels of QoL. However, further investigation is necessary to determine this.

\section{Limitations}

The cross-sectional nature of the study limits the investigation into causal relationship between determinants and outcomes of interest (malnutrition). Likewise, further comparative study between HIV-infected and nonHIV infected persons could explore additional nutrition and food security risk factors. The study, like others, is subject to some systematic errors, including measurement error, recall bias for self-reported components, and incomplete medical records. These are the key limitations. Additionally, self-reported HRQoL measures may feature important confounds, in that some aspects of HRQoL may also be affected by factors in a study participants life unrelated to nutrition status or HIV and AIDS that nevertheless affect their answers.

\section{Conclusions}

In our findings, one in every five PLHIV is undernourished. Nutritional status was found to be positively correlated with QoL. Although further longitudinal research will be helpful in determining the role of nutritional status in QoL, the results of this study suggest that the existing care options for PLHIV do not appear to fully address this issue. Nutritional support should form a fundamental part of the response to HIV and AIDS in Nepal, including more efforts toward providing nutritional counseling, support, and encouragement to clients. Our results also make a case for a PLHIV-specific food security program, additional to ones targeting HIV-negative food-insecure populations, to ensure this especially vulnerable population receives adequate support.

\section{Competing interests}

The authors declare that they have no competing interests.

\section{Authors' contributions}

RT, DPP and KB designed, implemented and drafted the manuscript. MSN analyzed the data and revised the paper. AA is responsible for overall supervision of the research process and reviewed the article. All the authors have read and approved the final manuscript.

\footnotetext{
Acknowledgements

We would like to acknowledge the support of Prof. Dr. Prem Krishna Khadga, TUTH, Dr. Anup Bastola, Dermatologist, STIDH, Mr. Madhav Pant, ART counselor, TUTH, Ms. Uma Chitrakar, TUTH, for their support in carrying out and successfully complete this study. We are grateful to all the participants. We also offer sincere and earnest thankfulness to Prof. Dr. Amod Poudel, who helped us with the analysis, and the entire team of TUTH, Department of Community Medicine and Public Health for their support and help which made this study possible and feasible. Our sincere thanks goes to Ms. Barsha Thapa, Mr. Deepak Jha and Ms. Anita Shrestha for their active help and assistance during data collection and analysis. RT adds special thanks to all her friends in the MPH program 15th Batch for their kind assistance.
}

\section{Funding of the Project}

This is a self-funded project with the technical support from the Institute of Medicine, Maharajgunj, Kathmandu.

\section{Author details}

'Institute of Medicine, Maharajgunj Medical Campus, Tribhuwan University, Kathmandu, Nepal. ${ }^{2}$ James P Grant School of Public Health, BRAC University, Dhaka, Bangladesh. ${ }^{3}$ Independent Scholar, Chicago, IL, USA.

Received: 7 February 2015 Accepted: 14 April 2015 Published online: 03 May 2015

\section{References}

1. Joint United Nations Programme on HIV/AIDS (UNAIDS). The Gap Report. Geneva: UNAIDS. 2014. Available at: http://www.unaids.org/sites/default/ files/en/media/unaids/contentassets/documents/unaidspublication/2014/ UNAIDS_Gap_report_en.pdf.

2. Joint United Nations Programme on HIV/AIDS (UNAIDS). Fast-track: ending the AIDS epidemic by 2030. Geneva: UNAIDS; 2014. Available at: http:// www.unaids.org/sites/default/files/media_asset/JC2686_WAD2014report_en.pdf.

3. Trujillo EB, Borlase BC, Bell SJ, Guenther KJ, Swails W, Queen PM, et al. Assessment of nutritional status, nutrient intake, and nutrition support in AIDS patients. J Am Diet Assoc. 1992;92(4):477-8.

4. World Health Organization: Nutrient requirements for people living with HIV/ AIDS: report of a technical consultation. Geneva, Switzerland 2003. Available at: http:/www.who.int/nutrition/publications/hivaids/9241591196/en/.

5. Maertens, JA. Barriers to Nutrition management among people living with HIV on Antiretroviral Therapy. Dissertation for Doctor for philosophy. 2011. Available at: http://digitool.library.colostate.edu/exlibris/dtl/d3_1/apache_media/ L2V4bGlicmlzL2R0bC9kM18xL2FwYWNoZV9tZWRpYS8xMTC00DA=.pdf.

6. Anand D, Puri S, Mathew M. Assessment of Quality of Life of HIV-Positive People Receiving ART: An Indian Perspective. Indian J Community Med. 2012;37(3):165.

7. Hsu JW, Pencharz PB, Macallan D, Tomkins A. Macronutrients and HIV/AIDS: A Review of Current Evidence in Consultation on Nutrition and HIV/AIDS in Africa: Evidence, Lessons and Recommendations for Action. Durban, South Africa: WHO, Department of Nutrition for Health and Development; 2005.

8. PEPFAR. Report on Food and Nutrition for People Living with HIV/AIDS. 2006.

9. Anema A, Vogenthaler N, Frongillo EA, Kadiyala S, Weiser SD. Food insecurity and HIV/AIDS: current knowledge, gaps, and research priorities. Curr HIV/AIDS Rep. 2009;6(4):224-31.

10. Palermo T, Rawat R, Weiser SD, Kadiyala S. Food Access and Diet Quality Are Associated with Quality of Life Outcomes among HIV-Infected Individuals in Uganda. PLoS One. 2013;8(4):e62353. doi:10.1371/journal.pone.0062353.

11. Food and Nutrition technical Assistance (FANTA) and World Food Program (WFP). Food Assistance Programming in context of HIV. Washington, DC: FANTA Project, Academy for Educational Development; 2007.

12. Bhowmik A, Ghugre P, Udipi S, Guha SK. Nutritional Status and Quality of Life of Women with HIV/AIDS. Am J Infect Dis. 2012;8(1):13-8.

13. World Health Organization. Division of mental health and prevention of substance abuse. WHOQOL and spirituality, religiousness and personal beliefs (SRPB). WHO;1998.

14. Ruutel K, Pisarev H, Loit HM, Uuskula A. Factors influencing quality of life of people living with HIV in Estonia: A cross-sectional survey. J Int AIDS Soc. 2009;12:13.

15. Louwagie G, Bachmann M, Meyer K, Booysen FIR, Fairall L, Heunis JC. Highly active antiretroviral treatment and health related quality of life in South African adults with human immunodeficiency virus infection: a crosssectional analytical study. BMC Public Health. 2007;7(244):1-33.

16. Folasire OF, Irabor AE, Folasire AM. Quality of life of People living with HIV and AIDS attending the Antiretroviral Clinic, University College Hospital, Nigeria. Afr J Prm Health Care Fam Med. 2012;4(1):294.

17. Testa MA, Lenderking WR. The impact of AIDS-associated wasting on quality of life: qualitative issues of measurement and evaluation. J Nutr. 1999;129:282-9.

18. Venter E, Gericke GJ, Bekker PJ. Nutritional status, quality of life and CD4 cell count of adults living with HIV/AIDS in the Ga-Rankuwa area (South Africa). S Afr J Clin Nutr. 2009:22:124-129.

19. NCASC: Nepal Country Progress Report. Kathmandu: National Centre for AIDS and STD Control; 2014.

20. United Nations Development Programme(UNDP).Millennium Development Goals (MDG) Progress Report 2013. Available at: http://www.np.undp.org/ content/nepal/en/home/library/mdg/mdg-progress-report-2013.html.

21. Food and Agricultural Organization (FAO). Assessment of Food Security and Nutrition Situation in Nepal 2010. Available at: ftp://ftp.fao.org/TC/CPF/ Country\%20NMTPF/Nepal/thematic\%20studies/Food\%20Security\%20_ Final_.pdf. 
22. National Centre for AIDS and STD Control (NCASC). National Guidelines for Antiretroviral Therapy. Kathmandu: National Centre for AIDS and STD Control, Apr; 2012. Available at: http://www.who.int/hiv/pub/guidelines/nepal_art.pdf.

23. Nti A, Hayford J, Obisaw, CP. Nutrition Knowledge, Diet Quality and Nutritional Status of People Living with HIV (PLHIV) in Ghana. Food and Public Health 2012;2(6):219-227.

24. Daniel M, Mazengia F, Birhanu D. Nutritional Status and Associated Factors among Adult HIV/AIDS Clients in Felege Hiwot Referral Hospital, Bahir Dar. Ethiopia Science Journal of Public Health. 2013;1(1):24-31.

25. Kothari CR. Research Methodology Methods \& Techniques. 2nd ed. New Delhi: New Age International publisher; 2004.

26. NHRC. National Ethical Guidelines for Health Research in Nepal And Standard Operating Procedures. 2011. Available at http://nhrc.org.np/ guidelines.

27. WHO. WHO QoL HIVBREF. Department of Mental health and Substance Dependence. 2002.

28. Imam MH, Karim MR, Ferdous C, Akhter S. Health related quality of life among the people living with HIV. Bangladesh Med Res Counc Bull. 2011;37:1-6

29. Giri S, Neupane M, Pant S, Timalsina U, Koirala S, Timalsina S, Sharma S. Quality of life among people living with acquired immune deficiency syndrome receiving anti-retroviral therapy: a study from Nepal. Dove Press. 2013;277-282.

30. Coates J, Swindale A, Bilinsky P. Household Food Insecurity Access Scale (HFIAS) for Measurement of Food Access: Indicator Guide. Washington, DC: Food and Nutrition Technical Assistance Project (FANTA), Academy for Educational Development. 2007. Available at: http://www.fao.org/fileadmin/ user_upload/eufao-fsi4dm/doc-training/hfias.pdf.

31. Baiyegunhi LJS, Makwangudze KE. Home Gardening and Food Security Status of HIV/AIDS-Affected Households in Mpophomeni, KwaZulu-Natal Province. South Africa J Hum Ecol. 2013;44(1):1-8.

32. Weiser SD, Frongillo EA, Ragland K, Hogg RS, Riley ED, Bangsberg DR. Food Insecurity is Associated with Incomplete HIV RNA Suppression Among Homeless and Marginally Housed HIV-infected Individuals in San Francisco. J Gen Intern Med. 2009;24(1):14-20. doi:10.1007/s11606-008-0824-5.

33. Kadiyala S, Rawat R, Babirye F, Ochai R. Food security is strongly associated with nutritional status mong HIV-infected individuals in Uganda: AIDS 2010 - XVIII International. AIDS Conference: Abstract no. CDB0046.

34. Mangili A, Murman DH, Zampini AM, Wanke CA. Nutrition and HIV infection: review of weight loss and wasting in the era of highly active antiretroviral therapy from the nutrition for healthy living cohort. Clin Infect Dis. 2006;42(6):836-42.

35. Xiong K. Review of the Evidence: Linkages between Livelihood, Food Security, Economic Strengthening, and HIV Related Outcomes. Measure Evaluation, 2012. Available at: http://www.cpc.unc.edu/measure/ publications/sr-12-71.

36. Ministry of Health and Population (MOHP) [Nepal], New ERA, \& ICF International Inc. Nepal Demographic and Health Survey 2011. Kathmandu, Nepal : Ministry of Health and Population, New ERA, and ICF International, Calverton, Maryland. 2012.

37. WHO. Regional Consultation on Nutrition and HIV and AIDS: Evidence Lesson Learnt and recommendation for action in South East Asia. 2007. p. 8-11.

38. Houtzager, LM. Nutrition in HIV: A Review. Nutrition Development Division, Albion Street Centre, Sydney, Australia

39. Kaiser JD, Campa AM, Ondercin JP, Leoung GS, Pless RF, Baum MK. Micronutrient supplementation increases CD4 count in HIV-infected individuals on highly active antiretroviral therapy: a prospective, double-blinded, placebo-controlled trial. J Acquir Immune Defic Syndr. 2006;42:523-8.

40. Tirivayi N, Koethe J, Groot W. Clinic-Based Food Assistance is Associated with Increased Medication Adherence among HIV-Infected Adults on Long-Term Antiretroviral Therapy in Zambia. Journal of AIDS and Clinical Research. 2012;3:171.

41. Ndekha MJ, van Oosterhout JJ, Zijlstra EE, Manary M, Saloojee H, Manary MJ. Supplementary feeding with either ready-to-use fortified spread or corn-soy blend in wasted adults starting antiretroviral therapy in Malawi: randomised, investigator blinded, controlled trial. BMJ. 2009:338:b1867.

42. Gichunge CN, Hogan J, Sang E, Wafula S, Mwangi A, Petersen T et al. Role of food assistance in survival and adherence to clinic appointments and medication among HIV-infected patients on antiretroviral therapy (ART) in Western Kenya. Vienna: XVIII International AIDS Conference; 2010.
43. Unge C, Sodergard B, Marrone G, Thorson A, Lukhwaro A, Carter J, et al. Long-term adherence to antiretroviral treatment and program drop-out in a high-risk urban setting in sub-saharan Africa: a prospective cohort study. PLoS One. 2010;5(10):e13613.

44. Hailemariam S, Bune GT, Ayele HT. Malnutrition: Prevalence and its associated factors in People living with HIV/AIDS, in Dilla University Referral Hospital. Archives of Public Health. 2013;71(1):13. doi:10.1186/0778-7367-71-13.

45. Somarriba G, Neri D, Schaefer N, Miller LT. The effect of aging, nutrition, and exercise during HIV infection. HIV/AIDS. Research and Palliative Care. 2010;2:191-20.

46. Bhargava A, Chatterjee M, Jain Y, Chatterjee B, Kataria A, Bhargava, M, et al. Nutritional Status of Adult Patients with Pulmonary Tuberculosis in RuralCentral India and Its Association with Mortality. PLoS ONE 2013,. doi:10.1371/journal.pone.007797

47. Macallan DC. Malnutrition in tuberculosis. Diagn Microbiol Infect Dis. 1999:34:153-7. doi: 10.1016/S0732-8893(99)00007-3 PubMed:0354866.14.

48. Schaible UE, Kaufmann SH. Malnutrition and infection: complex mechanisms and global impacts. PLoS Med. 2007;4:e115. doi:10.1371/ journal.pmed.0040115.

49. Nnyepi MS. The risk of developing malnutrition in people living with HIV/ AIDS: Observations from six support groups in Botswana. S Afr J Clin Nutr. 2009;22(2):89-93.

50. Paton NI, Sangeetha S, Earnest A, Bellamy R. The impact of malnutrition on survival and the CD4 count response in HIV-infected patients starting antiretroviral therapy. HIV Med. 2006;7:323-30. doi:10.1111/j.1468-1293.2006.00383.x.

\section{Submit your next manuscript to BioMed Central and take full advantage of:}

- Convenient online submission

- Thorough peer review

- No space constraints or color figure charges

- Immediate publication on acceptance

- Inclusion in PubMed, CAS, Scopus and Google Scholar

- Research which is freely available for redistribution 